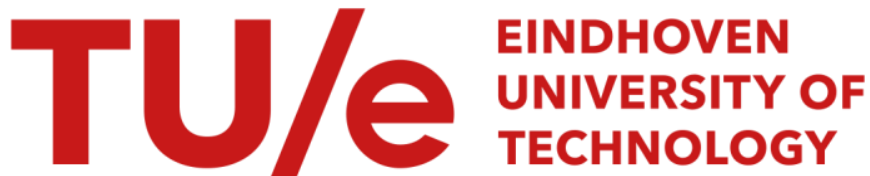

\section{Utilising residential flexibility in the planning of LV networks}

\section{Citation for published version (APA):}

Reinders, J., Bernards, R., Geldtmeijer, D. A. M., Morren, J., \& Slootweg, J. G. (2017). Utilising residential flexibility in the planning of LV networks. In 24th International Conference \& Exhibition on Electricity Distribution (CIRED): Session 5: Planning of power distribution systems, 12-15 June 2017, Glasgow, Scotland (pp. 25762580). [0381] (CIRED - Open Access Proceedings Journal; Vol. 2017-1). Institution of Engineering and Technology (IET). https://doi.org/10.1049/oap-cired.2017.0381

DOI:

10.1049/oap-cired.2017.0381

Document status and date:

Published: 01/10/2017

\section{Document Version:}

Publisher's PDF, also known as Version of Record (includes final page, issue and volume numbers)

\section{Please check the document version of this publication:}

- A submitted manuscript is the version of the article upon submission and before peer-review. There can be important differences between the submitted version and the official published version of record. People interested in the research are advised to contact the author for the final version of the publication, or visit the $\mathrm{DOI}$ to the publisher's website.

- The final author version and the galley proof are versions of the publication after peer review.

- The final published version features the final layout of the paper including the volume, issue and page numbers.

Link to publication

\section{General rights}

Copyright and moral rights for the publications made accessible in the public portal are retained by the authors and/or other copyright owners and it is a condition of accessing publications that users recognise and abide by the legal requirements associated with these rights.

- Users may download and print one copy of any publication from the public portal for the purpose of private study or research.

- You may not further distribute the material or use it for any profit-making activity or commercial gain

- You may freely distribute the URL identifying the publication in the public portal.

If the publication is distributed under the terms of Article 25fa of the Dutch Copyright Act, indicated by the "Taverne" license above, please follow below link for the End User Agreement:

www.tue.nl/taverne

Take down policy

If you believe that this document breaches copyright please contact us at:

openaccess@tue.nl

providing details and we will investigate your claim. 


\title{
Utilising residential flexibility in the planning of LV networks
}

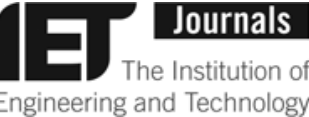

Engineering and Technology

ISSN 2515-0855 doi: 10.1049/oap-cired.2017.0381 www.ietdl.org

\author{
Jeroen Reinders ${ }^{1} \bowtie$, Raoul Bernards ${ }^{1}$, Danny Geldtmeijer ${ }^{1,2}$, \\ Johan Morren ${ }^{1,2}$, Han Slootweg ${ }^{1,2}$ \\ ${ }^{1} T U$ Eindhoven, Eindhoven, The Netherlands \\ ${ }^{2}$ Enexis BV, 's-Hertogenbosch, The Netherlands \\ $凶$ E-mail: j.reinders@tue.nl
}

\begin{abstract}
This study proposes and demonstrates a probabilistic approach to simulating low-voltage (LV) networks, which can incorporate flexibility in (future) household load. This method provides insight in probabilities of power flows and voltage magnitudes occurring, and can therefore predict chances of overloading cables and violating voltage limits. Compared with the current planning method (worst case approach) for LV networks, this allows for a more accurate estimation of risk levels when designing the network. Incorporation of user activated flexibility can influence the probability of power flows or voltage magnitudes occurring, but cannot reliably prevent violating limits altogether.
\end{abstract}

\section{Introduction}

Increasing numbers of major electricity consuming appliances in households, such as heat pumps (HPs) and electric vehicles (EVs), cause the peak in electricity use to rise. In addition to that, increasing photovoltaic (PV) power production may cause a peak in opposite direction (electricity supply) at another moment in time. These new appliances bring with them an uncertainty to the future load development of the electricity grid for distribution system operators (DSOs). Especially on the low-voltage (LV) grid level, uncertainty in loading will increase as the increasingly unpredictable character of residential loads is of greatest impact here.

Demand-side management (DSM) poses a possible solution for these problems, providing a means to influence electricity demand and therefore diminish the impact on the electricity grid. However, the current planning approach is not adequate to properly take DSM into account as network planning options for the LV grid. Nor can it consider the stochastic nature of decentralised generation.

This paper presents a probabilistic approach to simulating LV networks. First, the differences between deterministic and probabilistic planning methods are discussed. Next, the probabilistic planning method is described and what data is used. Results from simulations are compared with deterministic planning and the impact of flexibility in (future) residential loads is determined. This paper builds on results reported in [1], investigating the impact of household's flexibility in LV network planning.

\section{Deterministic planning}

Current (deterministic) planning of LV networks is mostly done using a peak-planning approach, based on the maximum expected household load during the year. This maximum load (worst-case approach) is used in combination with key figures for its simultaneity with other households in the network. This is done as the highest combined power (of households) is always lower than the maximum power of the individual households combined. The Strand-Axelsson (SA) method relates the maximum average power use of households to the yearly energy use [2]

$$
P_{\max , n}=\alpha E_{1} n+\beta \sqrt{E_{1} n}
$$

The maximum power use $\left(P_{\max , n}\right)$ of $n$ households in an LV network can be calculated from one household's yearly energy use $\left(E_{1}\right)$, where $\alpha$ and $\beta$ parameters are determined empirically. This method is valid when multiple household loads are evenly divided among phases and in radial LV networks.

LV networks are planned to be able to cope with increasing loads for 30 years. A percentage of yearly increase of electricity use is determined, based on previous years. This increase in loading accounts for an increase in connections to the electricity grid, as well as an increase in loading due to behaviour.

Currently, there is no standard procedure to take an increasing penetration of HP, EV, and PV panels into account. The trend in LV network planning is 'better safe than sorry', designing networks that can cope with large increase in loads and big simultaneity factors [2]. Owing to this way of calculating, the full capacity of the network is rarely utilised.

\section{Probabilistic planning}

The literature suggests probabilistic analysis methods as a favourable way to calculate the impact of future loads in current LV network topology. A probabilistic planning method can better take the stochastic character of PV production into account [3], more accurately determine occurring peak loads [4] with penetration of new appliances, and take flexible loads into account [5].

Monte Carlo simulation is used for probabilistic LV network design. The Monte Carlo technique substitutes a range of values (probability function) for the input variables of the calculation. The simulation is carried out multiple iterations to yield a result with a probability of occurring [6].

Instead of having one value for loading of a household (peak load in current planning method), the Monte Carlo method will sample one possible value for household loading for each calculation, from a probability curve.

\section{Method}

Simulation of LV networks is carried out in three steps. Firstly, the network loading is determined by using the current (deterministic) approach. Secondly, the same network is simulated stochastically, sampling values for household loading from a real-life measured 
data set. Finally, the network is simulated stochastically again, now adding PV, EV, HP, and flexibility.

\subsection{Measurement data}

For stochastic LV network planning, data is required representing the probability of a certain power occurring at a given time. This data is collected for households (current loading), EVs, HPs, and solar radiation. Household power consumption data is retrieved from DSO Liander open data database. This data consists of actual smart meter data of 80 households for the year 2013 [7]. Data for EVs is supplied by ElaadNL, providing measured data for charging stations of EVs for the year 2015. Of this EV data, charging profiles matching expected residential charging patterns are selected. For solar irradiation, data is taken from the royal Dutch meteorological institute (KNMI) Data Centre, providing solar irradiation data for 10 years (2003-2013) in the Netherlands. DSO Enexis provides expected solar PV system size and peak power production [8] for an average household based on free roof area. Solar panel efficiency is chosen accordingly at $15 \%$. HP data is retrieved from the Jouw Energie Moment pilot, analysed in [1], this is actual measured data for power consumption of HPs $\left(2 \mathrm{~kW}_{\mathrm{e}}\right)$ for 30 households from March 2013 until March 2014. Of crucial influence on the power use of HPs is that the HPs in this set do not have an electrical element for heating. As measurements for only 1 year are available, HPs are sampled based on outside temperature. This way, we decouple the temperature that has occurred in the measured year at a certain time from the data set. For sampling temperatures, data is taken from the KNMI Data Centre for the years 1988-2015.

\subsection{Flexibility of households}

Investigating DSM, several Western European pilots addressed the possibility of activating flexibility in electricity use of residential customers. In [1], flexibility is reported as an average change in household load (for household load, HPs, and EVs) per hour of the day. The Low Carbon London pilot (analysed in [1]) found that flexibility not only lowers average power consumption (during high price moments) but also decreases variance in the power use of customers [9]. These results are hard to reproduce for other flexibilities, as there is no indication by what value the variance should decrease. As flexibility has an impact on average power use, the simplest way to represent flexibility is by shifting the power use probability curve towards a lower (or higher) average. Assuming the Low Carbon London results hold, this is even underestimating flexibility, but relatively straightforward to implement.

The presented way of dealing with flexibility causes the need to represent flexibility as a change in average load profile. This means that, rather than adding flexibility to a calculation as an extra stochastic variable, flexibility is represented as a change in load profile of the appliance to which the flexibility applies. Assumed is that the only incentive that can be given is either 'provide flexibility' or 'do not provide flexibility'. This means that full (stochastic) flexibility potential is given when asked and the normal load curve is followed when no flexibility is asked. Another assumption is that the goal of the DSO is to reduce peak power usage. Therefore, incentive for lowering power is assumed from 16:00 until 0:00, when peak power occurs. Incentive for increasing power is assumed from 0:00 until 6:00, when power demand is low. The preferred load profiles are constrained to yield the same energy use over the day as the current load profile, the requested increase in energy use equals the decrease in energy use at another time. This way the average load curve will be affected as shown in Fig. 1.

In order to prevent a new peak load due to EVs providing more power increase than needed, extra (active) control of charging stations is assumed. This means that the EV preferred power use curve does not follow the maximum line of increase.
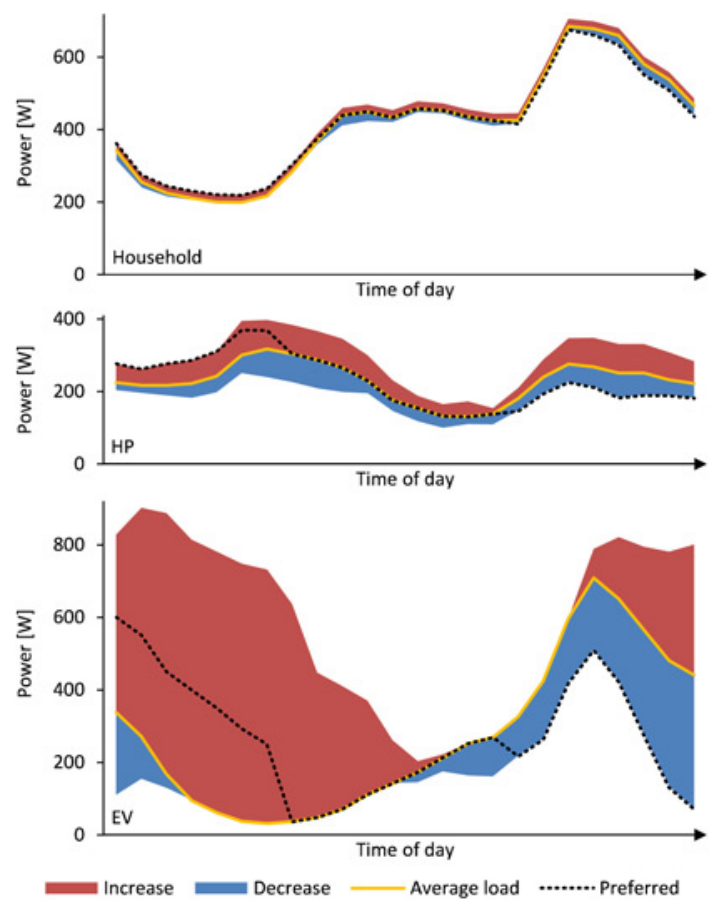

Fig. 1 Flexibility added to average load curve for households, HPs, and $E V$ s. Flexibility increase and decrease potential visualised around average load curve. Preferred load curve for lowering peak loads depicted

Applying flexibility to the stochastic load of a household in the simulated network means either adding or subtracting the requested flexibility from the randomly sampled data.

\subsection{Stochastic simulation of LV networks}

LV networks are simulated stochastically using Matpower [10], a Matlab-based simulation software for power flow simulations. In Matpower, an LV network is modelled. This network is used to solve AC power flows, both deterministically and stochastically. By modelling each household in the network as a power consuming and producing node, each household's power can be set independently.

This simulation process is carried out on a real-life example network, taken from the Hermes DG3 project [11]. From this research, the most critical network is selected, and from this network, the most critical cable is chosen. This is cable $\mathrm{C}$ of the LV network in the town of Epse in the Netherlands, which is shown schematically in Fig. 2. In the figure, we see a feeder departing from the LV bus at an MV/LV substation, this feeder has two branches on it. The network has in it 55 households, represented as arrows departing from the branches.

Simulation is done using 15 min resolution, for each quarter of an hour, a power is sampled for each household in the network.

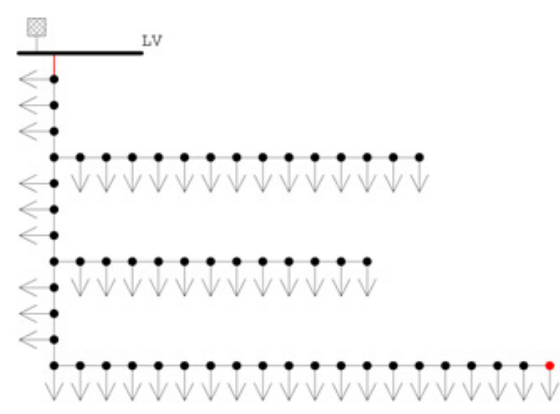

Fig. 2 Network Epse, as used for simulations 


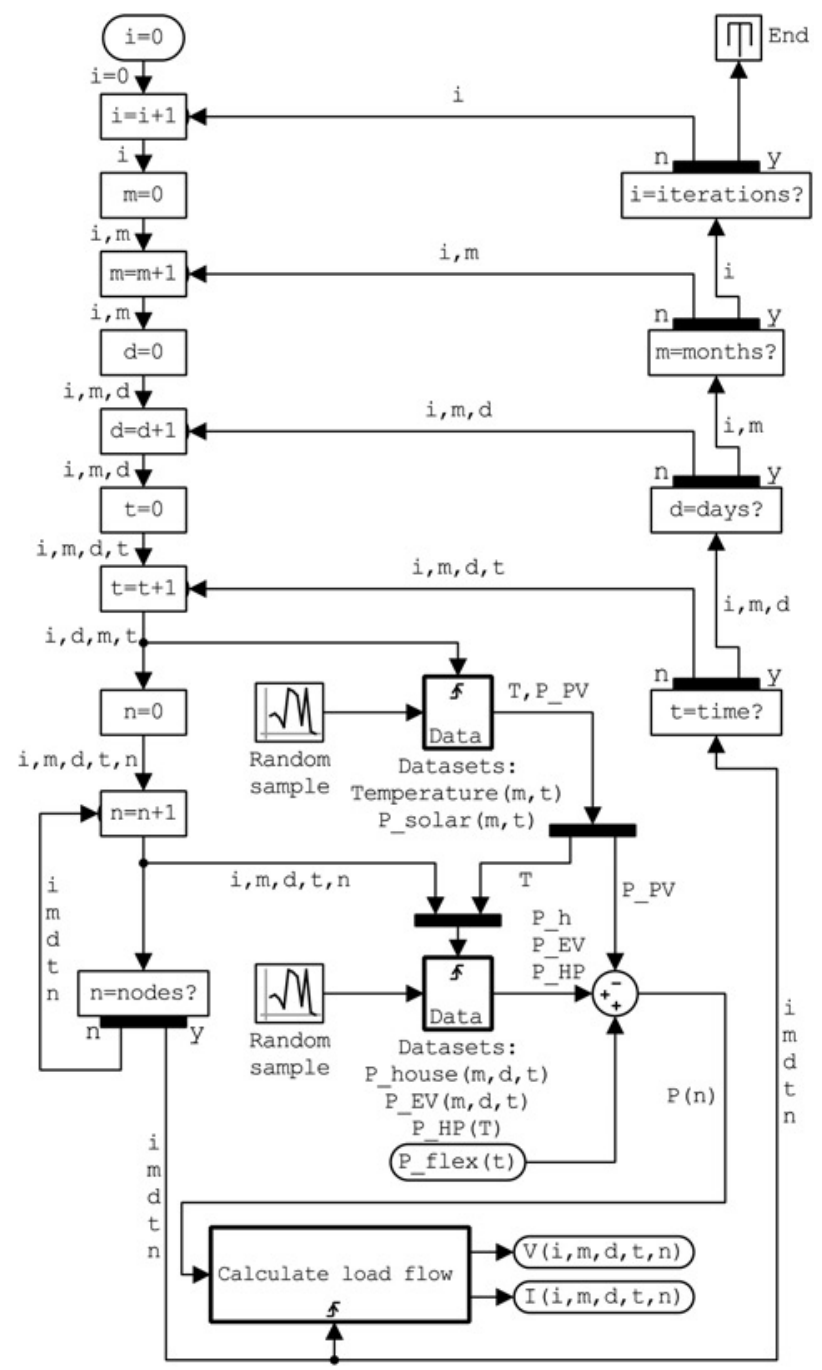

Fig. 3 Simulation process

Differences in power demand can be seen between months, and between weekdays and weekend days. Measurements of weekdays and weekend days are aggregated per month. Fig. 3 represents the simulation process. Showing simulations cycles for $i$ iterations, $m$ months, a weekday and a weekend day $(d)$, for each quarter of an hour during the day $(q)$, and for $n$ nodes in the network. This results in voltages $(V)$ and currents $(I)$ for each node for all simulations (iterations $\times$ months $\times$ days $\times$ times).

\subsection{Determining the number of iterations}

The number of iterations carried out in a Monte Carlo simulation determines its confidence interval. If more iterations are carried out, greater confidence can be obtained for the result [6]. There is a trade-off to be made between the precision required and the time needed for calculations.

The Kullback-Leibler (KL) divergence is used to determine the information gain of each consecutive iteration. The KL divergence gives a relative measure for the uncertainty of a probability distribution [12]. Often the KL divergence is used as a measure for the amount of information lost by approximating one distribution function with the other. For discrete probability distributions, $P$ and $Q$, the KL divergence is defined [12] as

$$
D_{\mathrm{KL}}(P \| Q)=\sum_{x} P(x) \log \frac{P(x)}{Q(x)}
$$

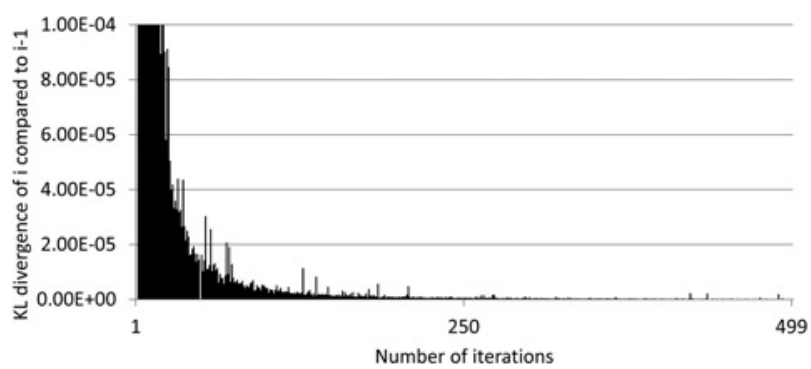

Fig. $4 K L$ divergence $(i / / i-1)$ for number of iterations

The minimum value KL divergence can reach is 0 , meaning two distribution functions are identical.

Determining the KL divergence during the process of iterating means that we can evaluate how much more information is gained by carrying out another iteration. More iterations provide more information, by comparing the $i$ th iteration to the $i-1$ th iteration, we see the information lost by approximating iteration $i$ by iteration $i-1$. Because of the way the network is simulated, each iteration in the process represents 1 year. During one iteration, $2304(96 \times 2 \times 12)$ samples are taken from data sets. This causes the KL divergence to reach low values relatively fast, as can be seen in Fig. 4, showing KL divergence for 1 to 500 iterations for household loading in the Epse network.

During the process of sampling data, each moment in time is assumed to be independent of the others. This means that there is no correlation taken into account when sampling data, even though one might expect this correlation to be there. If power use of e.g. an HP has been high during moment $t$ because the temperature has been low, it is likely to still have a high power use at $t+1,15 \mathrm{~min}$ later. With high numbers of iterations, one can expect to still have covered all possibilities for power usages at several times. Because of this reason, it is chosen to execute at least 500 iterations when simulating the network, even though the KL divergence suggests a lower number of iterations would yield comparable results.

\section{Results}

Power flow results show the spread of results is largest at the beginning of the cable in the network, and the largest power flow occurs. The lowest voltage magnitude we see occurring at the node farthest away from the MV/LV substation. These two parts in the network (shown in red in Fig. 2) are most critical for overloading; therefore, these are used for analysing results when adding more appliances and flexibility.

In Fig. 5, we see simulation results for current household load in Epse network. The left figure shows the probability mass function for current in the first part of the cable. The right figure shows the voltage magnitude probabilities for the node farthest away from the substation. These probabilities are compared with SA calculated values (blue lines). The dark blue represents standard SA results, taking into account increasing loads for 30 years. The light blue line shows the results for an SA calculation in year 0 , representing the current situation. As the data set also represents
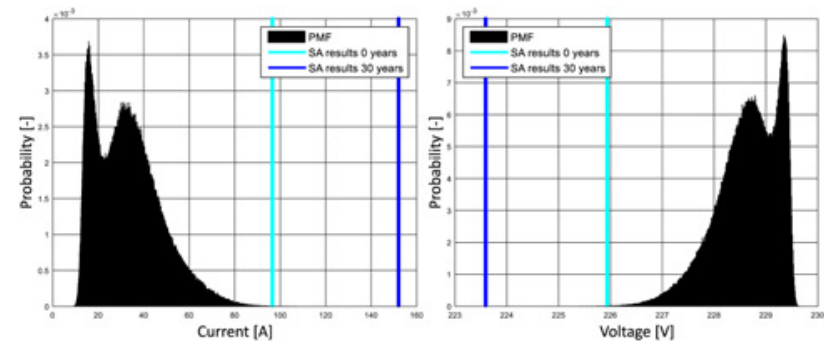

Fig. 5 Current and voltage magnitude results for Epse, household loads 

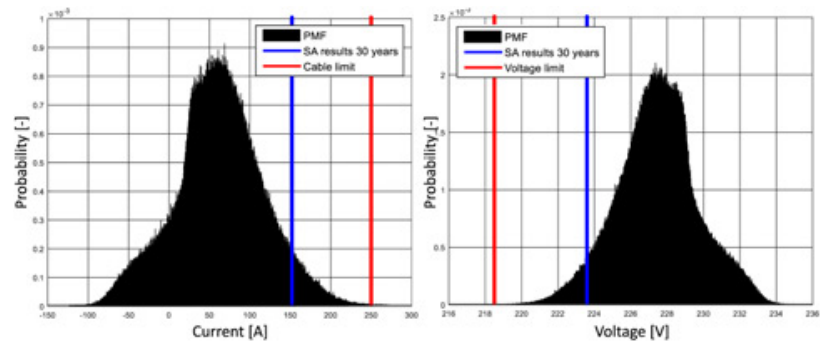

Fig. 6 Current and voltage magnitude results for Epse, with each household equipped with $H P, E V$, and $P V$
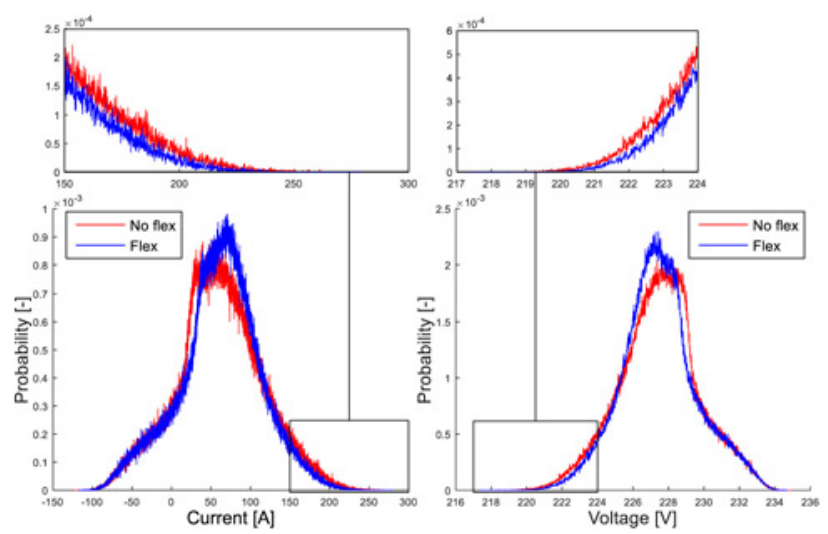

Fig. 7 Simulation results for current and voltage with or without flexibility in the Epse network

the current situation, these are compared. There is a small chance $(P=0.0091 \%)$ of the power flow exceeding the SA calculation for year 0 . Likewise, there is a small chance of a voltage magnitude occurring below the SA value for year $0(P=0.018 \%)$. We see there is very little chance of power flows and voltage magnitudes in a network actually reaching the SA calculated values. Which is to be expected from the approach taken in designing LV networks: 'better safe than sorry'.

We now add HPs $(2 \mathrm{~kW})$, PV systems $(1.8 \mathrm{~kW})$, and EVs to each household's load (Fig. 6). For current results, a $4.9 \%$ chance of exceeding the SA value is found. The cable limit is now shown in the figure (red line), this is the limit as given by DSO Enexis for a $150 \mathrm{Al}$ cable, at $250 \mathrm{~A}$. We see there now is also a $0.0053 \%$ chance of overloading the cable. The results for voltage magnitude show there is a $4.4 \%$ chance of voltages occurring lower than the SA value. For voltage magnitude, there is now a possibility of violating regulatory limits. There is a $0.0021 \%$ of a voltage occurring that is lower than the $5 \%$ maximum drop in voltage $(218.5 \mathrm{~V})$ between the MV/LV substation (set at $230 \mathrm{~V}$ ) and the node farthest away.

This means that the simulated network no longer complies with limits for both the cable and the voltage magnitudes. Flexibility is now added to the calculation to see if it can prevent the network from overloading. Fig. 7 shows the difference between applying flexibility (blue line) and not applying flexibility. The figure shows

Table 1 Chances of violating limits with or without flexibility in the Epse network

\begin{tabular}{lcc}
\hline Probability & No flex, $\%$ & Flex, \% \\
\hline power flow $>$ SA value & 4.9 & 3.4 \\
power flow $>$ cable limit & 0.0053 & 0.0012 \\
voltage magnitude $<$ SA value & 4.4 & 3.2 \\
voltage magnitude < voltage limit & 0.0021 & 0.0004 \\
\hline
\end{tabular}

small differences between applying flexibility or not. There is less chance of high power flows and LVs occurring if flexibility is applied. On the other hand, the average power flow and voltage magnitudes occur more often. Flexibility causes the network to become more predictable, but does not rule out extreme values. Table 1 shows a comparison between the simulation with and without flexibility.

\section{Conclusions}

We see that chances of overloading a network planned with current planning method are close to zero. As current planning is done for 30 years into the future, this method might still be effective, even if large-scale penetration of new appliances occurs. However, it lacks in providing information on the occurrence of peaks and could result (or: is currently resulting) in over dimensioned LV networks. Compared with current planning, probabilistic LV network planning allows for a more accurate estimation of the risk levels when designing the network.

Flexibility is shown to have little impact on the maximum power flow, or lowest voltage magnitude occurring. User activated flexibility can influence the probability of power flows or voltage magnitudes occurring, but cannot prevent violating limits altogether. Depending on whether certain chances of overloading the cable or violating voltage limits are found acceptable, flexibility can play a role in the planning of LV networks.

\section{Recommendations}

In this research, the power use at each time interval is assumed to be independent. Including this dependency may reduce the required number of iterations and calculation time. Adding time-dependency can also provide insight in the durations of overloading (e.g. $4 \mathrm{~h}$ per year occurring at once or several times $15 \mathrm{~min}$ ).

The data sets used for the simulations in this research could be improved. Household data now consist of average households; it may be interesting to split this up into types of houses. HP data was only available for 1 year and from houses in one street. A more elaborate data set could provide greater certainty of time-dependence of HPs. EV data is now taken from (semi-)public charging stations. Only charging stations that are assumed to show similar behaviour to household charging stations are used. Real measured data from household EV charging patterns would provide a better fit.

Another crucial data input missing in this research is the additional electrical element many HPs have. This may have major impact on results, as such electrical elements usually have a considerably higher rated power that the HP itself. A $2 \mathrm{~kW} \mathrm{HP}$ (as used in this research) can have an electrical element of $8 \mathrm{~kW}$.

Lastly, the penetration level of appliances is not taken into account in this research. Here, a $100 \%$ penetration is always assumed when simulating the future situation. The expected penetration of appliances could, for instance, also be integrated as a stochastic variable. The method provided can help investigate the impact of the penetration and the position in the network of new appliances on the LV network.

\section{References}

1 Bernards, R., Reinders, J., Klaassen, E.A.M., et al.: 'Meta-analysis of the results of European smart grid'. Proc. of the CIRED Workshop, Helsinki, Finland, 2016

2 van Oirsouw, P.M.: 'Netten voor distributie van elektriciteit (Dutch)' (Phase to Phase B.V., Arnhem, 2011)

3 Niederhuemer, W., Schwalbe, R.: 'Increasing PV hosting capacity in LV grids with a probabilistic planning approach'. 2015 Int. Symp. on Smart Electric Distribution Systems and Technologies (EDST), Vienna, 2015, pp. 537-540

4 Du, W.: 'Probabilistic analysis for capacity planning in smart grid at residential low voltage level by Monte-Carlo method', Procedia Eng., 2011, 23, pp. 804-812

5 Grond, M.O.W., Morren, J., Slootweg, J.G.: 'Integrating smart grid solutions into distribution network planning'. Proc. of the IEEE PES PowerTech 2013 Conf., Grenoble, France, 2013 
6 Graham, C., Talay, D.: 'Stochastic simulation and Monte Carlo Methods' (Springer, Berlin, Heidelberg, 2013)

7 Liander, N.V.: 'Open data - Slimme meter (Dutch)'. Data 2013

8 Enexis, B.V.: 'Netberekeningen LS- en OV-netten - GAIA modellering (Dutch)'. Ontwerpkaders 2013

9 Tindemans, S., Djapic, P., Schofield, J., et al.: 'Resilience performance of smart distribution networks'. Report D4 for the 'Low Carbon London' LCNF project, Imperial College, London, 2014
10 Zimmerman, R.D., Murillo-Sánchez, C.E., Thomas, R.J.: 'Matpower: steady-state operations, planning and analysis tools for power systems research'. IEEE Trans. Power Syst., 2011, 26, (1), pp. 12-19

11 van Lumig, M., Locht, M.: 'Impact DG en "nieuwe belastingen" op het LS-net in bestaande woonwijken (Dutch)'. Laborelec, stuurgroep HERMES DG 3, 2009

12 MacKay, D.J.C.: 'Information theory, inference, and learning algorithms' (Cambridge University Press, 2003), Version 7.0 (third printing) 25 August 2004 